\title{
Espaço, Identidade e Memória: O Lugar em Era Uma Vez Eu, Verônica
}

\author{
Space, Identity and Memory: \\ The Place in Once Upon a Time Verônica
}

\author{
Maria Helena Braga e Vaz da Costa ${ }^{i}$ \\ Universidade Federal do Rio Grande do Norte \\ Natal, Brasil
}

Resumo: Este trabalho explora os conceitos de identidade e memória, com o objetivo de entender como o espaço urbano da cidade de Recife-PE, representado no filme pernambucano Era Uma Vez Eu, Verônica (Marcelo Gomes, 2012), se constrói como lócus da identidade e da memória dos indivíduos que vivenciam o lugar contextualizado na realidade da vida urbana contemporânea. Apresenta-se aqui uma análise do discurso fílmico baseada nas reflexões e discussões desenvolvidas por teóricos como Stuart Hall (2005) acerca das identidades pós-modernas; Joël Candau (2011) sobre a dialética entre identidade e memória e o narrar como fonte de preservação do tempo, em acordo com uma visão antropológica; Yi-Fu Tuan (1983) e Edward Relph (2012) e suas noções de lugar, e das experiências que transformam o espaço em lugar interferindo na identidade do sujeito contemporâneo.

Palavras-chave: Espaço; Identidade; Memória; Lugar.

\begin{abstract}
This paper uses the concepts of identity and memory to understand how the city of Recife (Pernambuco) is represented in the film Once Upon a Time I Verônica (Era Uma Vez Eu, Verônica, Marcelo Gomes, 2012). This film portrays how this city is the locus for the construction of identity and memory for those who experience contemporary urban life. The discourse present in the film is analyzed using a post-modern identities framework of Stuart Hall (2005). The paper also explores the dialectic relationship between identity and memory in narrated preservation of time preservation as formulated by Joël Candau (2011). Finally, the ideas of Yi-Fu Tuan (1983) and Edward Relph (2012) concerning place and experience transforming space into place and interfering with individual identity are used to round out the theoretical framework.
\end{abstract}

Keywords: Space; Identity; Memory; Place.

\footnotetext{
i Professora Associada do Departamento de Artes e do Programa de Pós-Graduação Estudos de Mídia (PPGEM) e do Programa de Pós-Gaduação e Pesquisa em Geografia. mhcosta.ufrn@gmail.com.
} 


\section{Introdução}

Este trabalho reflete sobre os conceitos de identidade, memória e lugar, a partir de uma reflexão sobre a paisagem urbana da cidade de Recife - PE - construída no longa-metragem pernambucano Era Uma Vez Eu, Verônica (2012) ${ }^{1}$ escrito e dirigido por Marcelo Gomes. O objetivo aqui é, a partir da análise do discurso fílmico, tecer considerações sobre como as relações e as vivências humanas no espaço urbano contemporâneo podem ser acessadas e entendidas por analogia na relação com a representação da identidade e da memória dos personagens que vivenciam a realidade da vida urbana contemporânea.

Esse trabalho está dividido em duas partes: na primeira, intitulada Identidade e memória, introduzo a discussão sobre as diversas formas de identidades concebidas por Stuart Hall (2005) e trato da dialética existente na relação entre identidade e memória, e o ato de narrar como fonte de preservação temporal e da memória, em acordo com a visão antropológica de Joël Candau (2011). Em seguida, em Experiência, espaço e lugar da memória, e inspirada pelas discussões postas por Yi-Fu Tuan (1983) e Edward Relph (2012), discuto sobre como o lugar e a noção de "lar", e as experiências que transformam o espaço em lugar, interferem na identidade do sujeito contemporâneo.

\section{Identidade e Memória}

A Modernidade é definida como um período com identificação direta com a Revolução Industrial e o lluminismo - quando o homem enxerga a si mesmo como ser autônomo e centrado, capaz de atuar sobre a sociedade de forma autossuficiente. O processo de globalização iniciado no final do século XX trouxe consigo o esgotamento da modernidade e a superação de uma época a partir de crises ideológicas.

Nas sociedades contemporâneas e globalizadas, ditas pós-modernas por alguns autores, convivemos com mudanças constantes e permanentes que nos fazem refletir sobre a vida e o meio no qual estamos inseridos. O processo de globalização possibilitou uma maior interação entre as culturas e os sujeitos contemporâneos, um maior contato com o "Outro" (Costa, 2010). Isso produziu um impacto cultural sobre a identidade do sujeito que, em acordo com Stuart Hall (2005, p.7), "as velhas identidades, que por tanto tempo estabilizaram o mundo social [entraram] em declínio, fazendo surgir novas identidades e fragmentando o indivíduo moderno, até aqui visto como o sujeito unificado".

Hall apresenta os três tipos de identidade cultural formadoras do indivíduo: (1) a do Iluminismo: quando considera-se que o sujeito já nasce com uma identidade própria, autossuficiente, no qual o seu interior é centrado e unificado. Este acredita mais em si mesmo e suas concepções são as corretas sem interessar a opinião do outro; (2) a do sujeito sociológico: no qual o seu "eu interior" deixa de ser autônomo e passa a ser formado a partir da interação com o "outro" e a sociedade; e (3) a do sujeito pós-moderno: aquele que assume identidades diferentes em diferentes momentos, destituído de um "eu coerente". (HALL, 2005, p.13).

Na concepção de Hall, portanto, o indivíduo contemporâneo é resultado de uma mudança estrutural que tem transformado as sociedades modernas no final do século XX. Este sujeito "pós-moderno" responde à persistente fragmentação das paisagens culturais 
de classe, gênero, sexualidade, etnia, raça e nacionalidade, que, no passado, forneciam sólidas localizações para os indivíduos sociais. Em consequência, estas mudanças têm transformado as identidades pessoais, abalando a ideia que se tem de si próprio como sujeito integrado. (HALL, 2005)

Portanto, a identidade do sujeito contemporâneo é fragmentada na medida em que esta é afetada diretamente pelos tempos de aceleradas e momentâneas transformações tecnológicas e culturais. Hall explica:

Esta perda de um "sujeito de si" estável é chamada, algumas vezes, de deslocamento ou descentração do sujeito. Esse duplo deslocamento - descentração dos indivíduos tanto do seu lugar no mundo social e cultural quanto de si mesmos constitui uma "crise de identidade" para o indivíduo. (HALL, 2005, p. 9)

Podemos inferir, portanto, que na contemporaneidade (pós-modernidade) as identidades modernas entram em colapso. O sujeito "autoconstrói" um novo tipo de identidade conformada nas diferenças e que se contrapõe à noção de cultura unificada e de identidade intocável (COSTA, 2010). Dessa forma, o sujeito não mais é constituído por uma identidade fixa, mas múltipla, muitas vezes contraditória ou não resolvida. Este é o sujeito contemporâneo que no filme Era Uma Vez Eu, Verônica (2012) é caracterizado pela protagonista Verônica.

O filme de Marcelo Gomes trata da vida de Verônica (Hermila Guedes), nascida e criada em Recife, hoje com 24 anos e que mora com o pai enfermo, José Maria (Waldemar José Solha), a quem dedica cuidados e atenção constantes. Recém-formada em Medicina, a pernambucana trabalha como residente em psiquiatria em um hospital público da cidade. Absorvida com os problemas mentais de seus pacientes, e com a saúde do próprio pai, Verônica leva uma vida triste e melancólica resultante das angústias de uma rotina repleta de responsabilidades, cansativa e sem perspectiva de melhora.

É importante destacar que a paisagem recifense atua no filme como uma personagem que entra em constante diálogo com Verônica, e por vezes aparenta ser a "grande vilã" responsável pelos problemas materiais e conflitos existenciais da protagonista. Em entrevista durante o Festival Internacional de Cinema de San Sebastian, Marcelo Gomes (GOMES, 2012) comentou sobre a "participação" da cidade de Recife no filme. Para o cineasta, Recife apesar de ser uma cidade praiana e carnavalesca, que remete à festa e à alegria, é ao mesmo tempo barulhenta, caótica, suja e em pleno processo de crescimento desordenado. Isso, claro, reflete na vida de seus moradores causando crises existenciais, como é o caso da protagonista de Era Uma Vez Eu, Verônica.

As incertezas, inseguranças e frustrações de Verônica, advêm dos momentos caóticos vivenciados por ela nos espaços da cidade em que circula e no lugar que habita. $\mathrm{O}$ caos urbano de Recife, cidade em crescimento constante e acelerado, onde a especulação imobiliária prevalece, a violência é alta, o transito é confuso e as avenidas barulhentas, interfere na psique de boa parte da população. Sua profissão e o seu trabalho são reflexos de uma vida "vivida" em meio à sociedade contemporânea como a conhecemos - aquela que encontra sua gênese na modernidade. 
A escolha de Verônica pela psiquiatria nos parece uma tentativa de resolver não só os males e problemas psíquicos dos outros, mas os seus próprios. A personagem tem dúvidas sobre suas escolhas e a vida de maneira geral. Então, em uma espécie de exercício de autoajuda, grava uma conversa consigo mesma em seu gravador, e seu desabafo será posteriormente ouvido e analisado por ela própria. Aqui presenciamos Verônica como terapeuta de si mesma. Já no consultório, Verônica experimenta um processo de identificação com muitos de seus pacientes, pois as incertezas, inseguranças, medos e fobias descritos por eles são recorrentes. Significativo é o fato de Verônica associar os problemas psicológicos dos seus pacientes, e os seus próprios, à vida numa sociedade essencialmente urbana a qual denomina de "confusa".

Verônica tem consciência que o seu grande dilema é ter de lidar com os problemas dos seus pacientes diariamente e exaustivamente sem que sobre tempo para refletir e/ ou resolver os seus próprios. Tendo de lidar além disso com a doença do pai, Verônica se sente impotente e incapaz de superar seu sentimento de perda. Suas incertezas diante do futuro, da escolha da profissão, do relacionamento amoroso e a busca pelo seu "eu" interior são o espelho dos sujeitos contemporâneos que vivem nas grandes cidades modernas e cujas experiências no espaço e no tempo os colocam no centro da "crise de identidade" sugerida por Hall (2005).

Alusiva é a afirmação de Candau (2011) sobre identidade e memória estarem diretamente interligadas. Para explicar sua declaração o autor descreve um episódio ocorrido com o filósofo e escritor suíço, referência para o século XVIII, Jean-Jacques Rousseau: ao sofrer uma queda, Rousseau desmaia e, ao retomar a consciência, o filósofo não se lembra quem é. Candau então sugere que a perda da memória provoca a perda da identidade.

Sem memória o sujeito se esvazia, vive unicamente o momento presente, perde suas capacidades conceituais e cognitivas. Sua identidade desaparece. Não produz mais do que um sucedâneo de pensamento, um pensamento sem duração, sem a lembrança de sua gênese que é a condição necessária para a consciência e o conhecimento de si. (CANDAU, 2011, p. 59-60)

Assim, para Candau (2011), existe uma relação direta entre memória e identidade. Uma nutre a outra produzindo uma trajetória e uma narrativa de vida. A respeito disto lembremos o que diz Marilena Chauí: "A memória é uma evocação do passado. É a capacidade humana para reter e guardar o tempo que se foi, salvando-o da perda total" (CHAUÍ, 1998, p. 125). Aqui entra em evidência um outro elemento a ser considerado: a importância da narração nos processos de rememoração. Através do processo de narrar o sujeito ordena e torna coerente os acontecimentos e experiências de sua vida, no espaço e no tempo, que julga significativos (CANDAU, 2011). Dessa forma, o ato de narrar traz consigo a preservação das memórias para si mesmo e para os outros, já que nossas memórias são compartilhadas.

Na cena em que Verônica caminha pelo centro da cidade acompanhada de seu pai, ouvindo dele as histórias sobre uma Recife que ela não vivenciou - o antigo cinema de rua abandonado (Cine Trianon), a grande loja de departamentos (a Viana Leal) que sofreu transformações e desapareceu dando lugar primeiramente a uma igreja e depois se transformando em uma churrascaria - há claramente a construção narrativa do contraste entre 
a paisagem urbana do passado que é narrada a partir da memória do pai de Verônica, com a paisagem atual que visualizamos no filme e que nos é apresentada como deteriorada, poluída visualmente por gambiarras, pichações, grafites e cartazes espalhados pelos muros e paredes dos edifícios da cidade.

O sentido do lugar, tão fortemente evocado pela paisagem urbana, se faz presente na conexão construída pela ação e deslocamento dos personagens e uma estética do espaço composta por filmagens externas e planos gerais que são contrapostos aos closes das personagens em primeiro plano e a voz do personagem que narra suas impressões sobre o lugar. Recife tem sua paisagem explorada por uma série de imagens que privilegiam fragmentos do seu ambiente caótico, degradado e barulhento em contraponto com a narração reclamatória e saudosista do pai de Verônica. Esses fragmentos de espaços e tempos narrados remontam certa noção de identidade deste lugar chamado Recife.

Ainda sobre essa sequência, entendemos que o filme acena para uma "individualização da experiência", onde o individualismo tem conexão direta com o processo de fragmentação do sujeito e da sua experiência espacial e temporal, aquelas às quais Hall (2005) faz referência. Contrapondo narrativas (auditiva e visual), espaços e tempos (passado e presente) de uma cidade, esta sequência se apresenta como própria à representação fílmica; isto é, comentando sobre as mudanças e o caos urbano que a modernidade trouxe consigo e a pós-modernidade acomodou. ${ }^{2}$

É possível inferir que ao rememorar e compartilhar com a filha suas vivências na cidade por meio do ato de narrar, o pai de Verônica reconstrói o passado trazendo-o à tona no presente, ao mesmo tempo em que se utiliza da narração como forma de criticar o presente a partir da constatação, pelo olhar e pela experiência espacial, do estado de deterioração no qual se encontra o centro de Recife.

A sequência mencionada acima nos lembra da presença, na maioria das sociedades, de grupos que comparam seu passado, muitas vezes de forma inconsciente, à Era Dourada mitológica3, "como se tudo nos 'velhos tempos' em que viveram, estivesse em estado de apogeu e fosse melhor que o agora" (CANDAU, 2011, p. 88). A vivência aqui, então, é conformada a partir da "nostalgia de um passado idealizado" e de uma crise de identidade, já que o sujeito vive o presente na esperança de um futuro onde essa Era Dourada como tempo idealizado, retornaria. Podemos, então, traçar um paralelo entre a sequência fílmica descrita anteriormente e a posição de Candau sobre o sentimento nostálgico.

Muitas vezes manifestando nostalgia por um passado pintado com cores de "velhos bons tempos", o narrador faz uma crítica da sociedade atual que pode trair a exigência subjacente de mudanças para o futuro. O conteúdo da narrativa é, nesse caso, uma negociação entre uma certa representação do passado e um horizonte de espera. Por essa razão a memória, portadora de uma estrutura possível de futuro, é sempre uma memória viva. (CANDAU, 2011, p. 89)

\section{Experiência, Espaço e Lugar da Memória}

Se concordarmos com Yi-Fu Tuan (1983) para quem "a experiência implica a capacidade de aprender a partir da própria vivência" (p.10), podemos inferir que os espaços 
e lugares que "localizam" a experiência e a existência dos indivíduos, as cidades, por exemplo, também interferem e moldam suas vivências e suas identidades a partir do como estas são vivenciadas.

O apego ao lugar deriva da perspectiva da experiência cotidiana que o entende e percebe muitas vezes como o onde se tem raízes, sugerindo tanto o sentimento de uma profunda associação e pertencimento, mas, contraditoriamente, também o de imobilidade (RELPH, 2012). É esse sentimento que vincula Verônica ao passado, a sua infância tempo em que a narrativa parece assegurar como um tempo feliz e que está diretamente representado por um lugar: a casa em que viveu no passado e que não mais pertence a sua família. A casa da infância remete à ideia de lugar descrita por Tuan como "um arquivo de lembranças afetivas e realizações esplêndidas que inspiram o presente"; por isso mesmo, "o lugar é permanente e por isso tranquiliza o homem, que vê fraqueza em si e chance de movimento em toda parte" (TUAN, 1983, p.171).

Quando não está no trabalho, Verônica isola-se em seu quarto tornando este o seu lugar. Não um lugar com o qual se tem uma ligação mais forte, como aquele que traz à memória as experiências descompromissadas, e portanto felizes da infância, mas um refúgio onde a personagem pode refletir sobre a própria vida. A narrativa de Era Uma Vez Eu, Verônica confronta o espectador com a figura daquele indivíduo que Hall (2005) delineia como "isolado, exilado ou alienado, colocado contra o pano de fundo da multidão ou da metrópole anônima e impessoal" (p.32).

Nesse caso, a cidade de Recife é contraposta com a noção de lugar como um microcosmo; a partir do qual "cada um de nós se relaciona com o mundo e onde o mundo se relaciona conosco" (RELPH, 2012, p.31). Isolada em seu quarto, Verônica transforma esse espaço do apartamento em lugar; e é a partir deste lugar que a personagem relaciona seu mundo interior com a realidade cotidiana. Na cena em que Verônica canta o "Frevo da Saudade" (Nelson Ferreira), faz-se tácita a demonstração de que é no isolamento que a saudade se apresenta com mais intensidade. Saudade do passado, da infância, do "tempo de ouro" quando não havia espaço para tristeza, sofrimento, dúvidas, e preocupações acerca do futuro. Anne Muxel, citada por Candau (2011), se refere ao espaço do quarto como um lugar da memória:

Mesmo o próprio quarto, [...] é um lugar-refúgio privilegiado para a lembrança. Ele existe na memória como um espaço de isolamento entre si e os outros, como um primeiro envelope que informa alguma coisa de sua identidade e da negociação de um território próprio. (p. 158)

Impossível desconsiderar a citação acima na cena em que vemos Verônica em seu quarto, tocando violão e cantando uma composição de sua autoria. Nessa sequência, o quarto (lugar) de Verônica, sua música e os seus pensamentos são invadidos e interrompidos pelos constantes ruídos provenientes da cidade que adentram o espaço privado. Através da janela vemos um prédio em construção e todos os ruídos provenientes deste se sobressaem à voz de Verônica. Essa sequência é visivelmente um comentário sobre a impossibilidade de manutenção de um sentimento de pertencimento integrado ao "lugar-refúgio" na medida em que este é invadido e dissipado pela cidade. Seu crescimento 
desordenado, seus barulhos, seus habitantes, a multidão, interferem na vivência do lugar tanto quanto na personalidade e no estado psicológico da protagonista, abafando e sufocando sua fala, pensamentos e sentimentos.

Mesmo aceitando a ideia posta por Tuan de que "o lar é um lugar íntimo" e que "pensamos a casa como lar e lugar" (TUAN, 1983, p. 160), parece-nos que mesmo o lar de nossa infância, aquele que não mais habitamos, é o lugar onde foram construídas as bases das nossas experiências. O lar é uma referência de vida que permanece guardada na memória e molda nossa identidade. Mesmo que deixemos esse lugar, nos colocamos constantemente no movimento de busca por um outro espaço que o substitua trazendo de volta aquilo que vivenciamos no primeiro; isto é, os sentimentos e as certezas de pertencimento e de identidade com o lugar. É por meio desse processo de transformação de espaços vivenciados e/ou habitados em lugar que construímos estes e a eles conferimos significados. Como destaca Nogueira:

Significados que para alguns parecem invisíveis, mas para outros são carregados de histórias e de emoções. O lugar é um mundo de significados organizados, adquiridos pela experiência humana, e se mostra a partir do que eu experiencio e que é experienciado pelo outro, experienciar no sentido de viver. (NOGUEIRA, 2013, p. 84)

Portanto, podemos concordar com Santo Agostinho, citado por Tuan (1983, p. 156), quando propôs que "o valor do lugar dependia da intimidade de uma relação humana particular; o lugar em si pouco oferecia além da relação humana". É isto mesmo. O que nos "prende" aos lugares são as pessoas e não a substância material ou a paisagem. Nesse sentido, o significado de lar vai além da dimensão do material e do concreto. Lar representa e se constitui a partir das relações que temos com o Outro, das experiências que marcam os momentos vividos, e o lugar associado a essas experiências. Os lugares, portanto, "são a extensão da existência humana", pois são os indivíduos que dão sentido aos lugares "e neles estão misturados sentimentos, memórias individuais e coletivas" (NOGUEIRA, 2013, p. 85).

Novos sentidos podem também ser associados a alguns lugares se estes remeterem a uma memória não prazerosa, como a morte de alguém. A perda e/ou a ausência do outro pode trazer um novo sentido ao lugar transformando-o em um "cenário de tortura" (TUAN, 1983). O sentimento de pertença com o lugar nos faz reconhecer que as locações cinematográficas servem facilmente à dramaturgia e à exploração dos sentimentos dos personagens e/ou espectadores para com os espaços e lugares da cidade, pela utilização dos mesmos como elementos iconográficos. Como ressalta Allon a respeito dos espaços construídos e naturais utilizados como locação nos filmes: "Capazes de chamar a atenção do público e de recriar toda uma atmosfera, permitem o desencadeamento de associações mentais que reconstroem a paisagem, tal como já observado por Kevin Lynch em seu livro A Imagem da Cidade." (Allon, 2016, p.58)

É provável que a casa onde Verônica passou a infância tenha se tornado um lugar de tortura tanto para ela como para o seu pai após o falecimento de sua mãe. Memória de um passado atuando como possível origem dos distúrbios de então. É dessa forma 
explicado o fato de eles morarem em um apartamento no presente e a referência à casa aparecer quando o passado longínquo é mencionado. Mas é certo que o antigo lar da infância é local de memórias e tem significado nostálgico para os dois, mas principalmente para seu pai, que está sempre a recordar a vida em família e um tempo que passou - um bom exemplo é a insistência de José Maria em ouvir frevos antigos nos discos de vinil tocados em sua radiola ultrapassada. A narrativa coloca Verônica em uma posição dúbia no que se refere ao lugar e presenciamos em alguns momentos do filme a sua vontade (e intenção) de retorno a esse lugar, à casa da sua infância, que representa o lugar onde ela era mantida e cuidada por seu pai e não o contrário. Em acordo, remetemos às palavras de Tuan.

A consciência do passado é um elemento importante no amor pelo lugar. As pessoas continuam com os "pés fincados no chão" de suas experiências da infância ou do passado, mesmo após longos anos de afastamento. [...] Longínqua no tempo e, ao mesmo tempo, próxima/interiorizada espacialmente, a casa da infância, altamente significativa para a pessoa, pode ser desprovida de notoriedade para os outros, entretanto, para o indivíduo, atado por laços topofílicos ao passado, subsiste como símbolo de identificação imorredoura. (TUAN apud MELLO 2013, p. 60)

Os hábitos construídos pela vivência na cidade contemporânea e globalizada, associados à crescente especulação imobiliária, transformaram a paisagem recifense. Demolições de edifícios e "paisagens de uma vida inteira" (BOSI apud MELLO, 2013, p. 61), casas, que caracterizavam bairros antigos, foram substituídas por prédios que abrigam a classe média alta de Recife. A cidade se metamorfoseou tornando-se vertical. A casa em que Verônica passou a infância, e sua ainda resistência à especulação imobiliária em uma área da cidade que foi quase que totalmente renovada e verticalizada, é uma representação não apenas do seu lar, mas da memória de uma Recife que há muito desapareceu. A vontade expressa por Verônica de comprar a casa, agora em ruínas, demonstra a tentativa, não apenas de resguardar o lugar das memórias da sua infância, mas também de resgatar a memória da cidade como lugar. A imagem da casa no filme funciona como lembrança que vem e vai, como um "registro contemplativo" de um tempo que não é mais (ALLON, 2016). Essa reflexão me fez lembrar do que diz Milton Santos:

O passado passou, e só o presente é real, mas a atualidade do espaço tem isto de singular: é formada de momentos que foram, estando agora cristalizados como objetos geográficos atuais; essas formas-objetos, tempo passado, são igualmente tempo presente enquanto formas que abrigam uma essência, dada pelo fracionamento da sociedade total. Por isso, o momento passado está morto como "tempo", não porém como "espaço". (SANTOS, 2007, p. 14)

Em vista do exposto, podemos concluir que as mudanças constantes que a contemporaneidade trouxe para os espaços que se constituíram como da modernidade e para a sociedade, fez com que os indivíduos passassem a ver e sentir o mundo de outra forma. 
Verônica é o protótipo desse indivíduo contemporâneo que tem de lidar, além de tudo, com a crise de sua própria identidade. Seus problemas de pertencimento estão diretamente associados ao caos urbano característico da cidade contemporânea, e rememorar o passado é uma alternativa concreta para manter-se viva por meio da lembrança dos "bons tempos" que, mesmo com a certeza de que estes não retornarão, a memória do passado persiste em se apresentar como opção; contudo, não necessariamente como opção para uma sobrevivência menos traumática e mais sã.

Trazer a cidade de Recife para dialogar com personagem tão contemporânea quanto é Verônica, foi a opção de Marcelo Gomes que, como o mesmo atesta em entrevista, compartilha com a protagonista (e também com o espectador) seus próprios sentimentos e visões sobre a cidade de Recife e o que representa habitá-la e reconhecê-la enquanto lugar. O filme é uma representação de um sentimento saudosista por uma Recife que se transformou completamente e uma crítica sobre a consciência de que o mundo contemporâneo, como o entendemos, é ordenado pela transformação integrada, simultânea e indissociável do sujeito com o espaço da vivência, da cidade enquanto lugar.

\section{Referências Bibliográficas}

ALLON, F. Arquiteturas filmicas. Curitiba: Encrenca, 2016.

CANDAU, J. Memória e identidade. São Paulo: Contexto, 2011.

CHAUÍ, M. Convite à filosofia. São Paulo: Ática, 1998.

COSTA, M.H.B.V. Construções culturais - representações fílmicas do espaço e da identidade. Entre-Lugar, v.1, n.2, 2010, p. 17-32.

GOMES, M. Entrevista. Desayunos Horizontes, "Era Uma Vez Eu, Verônica", "La Demora", 2012. Disponível em: <www.youtube.com/watch?v=NY6B2QyBSe0>. Acesso em: 07 jun. 2016.

HALL, S. A identidade cultural na pós-modernidade. Rio de Janeiro: DP\&A, 2005.

MELLO, J. B. F. O triunfo do lugar sobre o espaço. In: Qual o espaço do lugar? Geografia, epistemologia, fenomenologia. MARANDOLA JR., E.; HOLZER, W.; OLIVEIRA, L. São Paulo: Perspectiva, 2012.

NOGUEIRA, A.R.B. Lugar como representação das existências. In: Maneiras de ler: geografia e cultura. HEIDRICH, A.L.; COSTA, B.P.; PIRES, C.L.Z. Porto Alegre: Imprensa Livre, 2013.

RELPH, E. Reflexões sobre a emergência, aspectos e essências de lugar. In: Qual o espaço do lugar? Geografia, epistemologia, fenomenologia. MARANDOLA JR., E.; HOLZER, W.; OLIVEIRA, L. São Paulo: Perspectiva, 2012. 
SANTOS, M. Pensando o espaço do homem. São Paulo: Edusp, 2007.

TUAN, Y. Espaço e lugar: a perspectiva da experiência. São Paulo: DIFEL, 1983.

Recebido em: 2/12/2016 Aceito em: 7/2/2017

\footnotetext{
${ }^{1}$ O filme Era Uma Vez Eu, Verônica participou da seção "Perspectiva Internacional" na $36^{\text {a }}$ Mostra Internacional de Cinema em São Paulo; competiu no $45^{\circ}$ Festival de Brasília do Cinema Brasileiro e conquistou sete prêmios: melhor filme pelo júri oficial, dividindo o prêmio com Eles Voltam, de Marcelo Lordello, melhor filme pelo júri popular, melhor ator coadjuvante, melhor roteiro, melhor fotografia e melhor trilha sonora; além do prêmio Vaga Lume de melhor longa-metragem.

${ }^{2}$ Podemos inclusive evocar a grande responsabilidade do próprio aparato cinematográfico na produção e representação da modernidade a partir das inúmeras possibilidades de visualização dos espaços urbanos das metrópoles que surgiam no período. Como bem destaca Allon (2016): "A maioria dos clichês urbanos advêm da metrópole do fim do século XIX: monumentos, meios de transporte, arranha-céus e população numerosa. Prédios históricos, igrejas, praças e acidentes naturais são também elementos emblemáticos dos quais se vale o cinema, impregnando-os com seu discurso e suas técnicas para determinadas intenções." (Allon, 2016, p. 58)

${ }^{3} \mathrm{O}$ termo deriva da mitologia grega e refere-se ao mais antigo período das idades de Ferro, Bronze, Prata e Ouro ao tempo no início da humanidade, que foi percebido como um estado ideal. A "Era Dourada" é conhecida como um período de paz, harmonia, estabilidade e prosperidade.
} 